\title{
تصميم طباعة أقمشة مكملات الملابس بتطبيق الفن الاختزالي
}

\section{Design of printing Clothes Appurtenances by application of The Minimal}

\author{
Art \\ أ.د./مايسة فكرى احمد السيد
}

أستاذ التصميم المتفرغ بقسم طباعة المنسوجات والصباغة والتجهيز ـكلية الفنون التطبيقية ـ جامعة حلوان.

Prof. Maysa Fikry Ahmed El-Sayed

Professor Emeritus of Design, Department of Textile Printing, Dyeing and Finishing -

Faculty of Applied Arts - Helwan University.

nanees27gamal@gmail.com

أ. م.د.انيفين فاروق حسين

أستاذ التصميم المساعد بقسم طباعة المنسوجات والصباغة والتجهيز ـ كلية الفنون التطبيقيةـ جامعة بنها.

Assist Prof. Dr. Nevin Farouk Hussein

Assistant Professor of Design, Department of Textile Printing, Dyeing and Finishing -

Faculty of Applied Arts - Benha University.

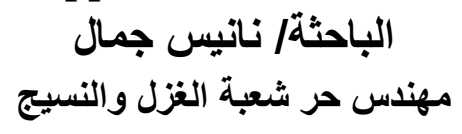

Researcher. Nanes Gamal

Freelance Engineer, Textile Division

dr_maysa@hotmail.com

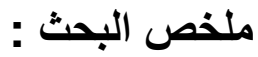

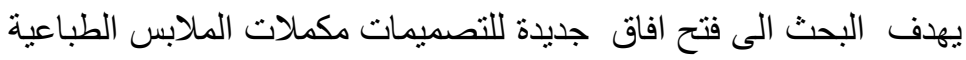

$$
\begin{aligned}
& \text { وتتلخص نتائج البحث فى وجود علاقه ايجابية بين المعالجات الفنيه التنككليه لبعض اعمال الفنانيين الاختز اليين وبين }
\end{aligned}
$$

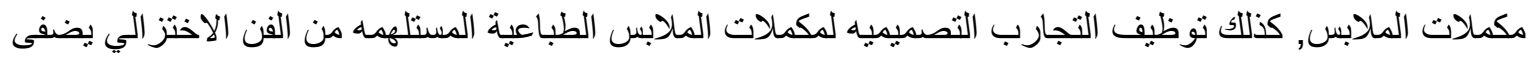

$$
\begin{aligned}
& \text { عليها قيم جماليه ونفعيه }
\end{aligned}
$$

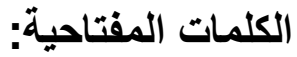

$$
\begin{aligned}
& \text { الفن الاختزالي، تصميم أقشة مكملات ملابس، التطبيق }
\end{aligned}
$$

\begin{abstract}
:
minimal art contains many aesthetic and artistic expressive and symbolic values, and despite the simplicity of reductionist art, it is a revolution in the classical style in plastic art, the problem of research lies in how to benefit from artistic treatments of some works of minmal artists to create print designs for clothing supplements that uplift the general taste For the Egyptian product.

The research aims to open new horizons for designs complementary to printing clothing The results of the research are summarized in the existence of a positive relationship between the formal artistic treatments of some works of reductionist artists and the supplementation of
\end{abstract}


clothing, as well as the employment of design experiments for complementary printing clothing inspired by reductionist art that imparts aesthetic and utilitarian values to it.

\section{Keywords:}

Clothe Appurtenances, The application, The minimal art

\section{:( Introduction)}

الفن هو افضل طريقة للتعبير التى توصل اليها الانسان فحين ندرس الفنون التى تركتها لنا تللك الحضار ات فلم يعرف اى نشاط أنسانى بالاستقر ار كما عرفت به الفنون التشكيلية. والفن موجود فى كل مكان فى شتى مظاهره مستمر ا وخالدا, فقد

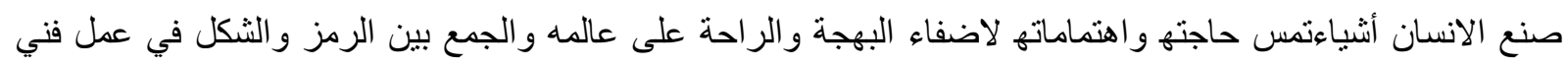
و احد لإثراء التعبير .ادى ذلك لظهور مصطلح الفن المعاصر في الغرب منذ ما بعد الستينات من القرن العشرين وامتدت ولته

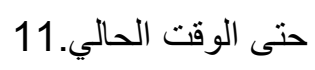

وتجسيدا مباثر الما اتي به الفن المعاصر * ظهرت من تللك الاتجاهات الفن الجماعي , فن الارض ,فن البيئة ,فن الاداء ,فن

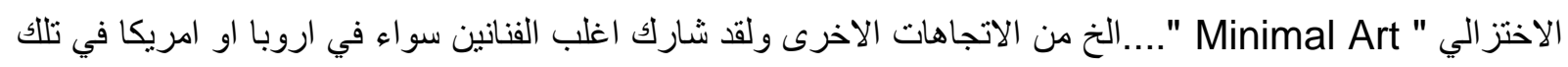
التجارب و الاتجاهات المتنو عة ,وكان لكل منهم اسهامه في التمهيد لتجارب اخرى التي تشعبت منها اتجاهات عديدة استمرت

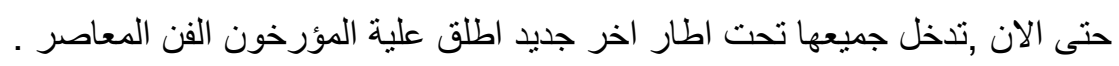
فن الاختز ال ما يعرف) (Minimal Art) هو اتجاه في الفنون و العمارة والادب ومجال الفنون المرئية و التصميم ,وازدهر في او اخر ستينات القرن العشرين بالو لايات المتحدة الامريكية1 ثم انتشر في باقي انحاء العالم ,وكان قائما على فكرة البحث

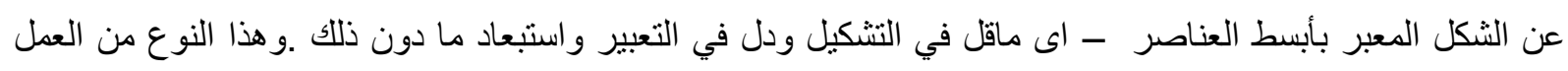

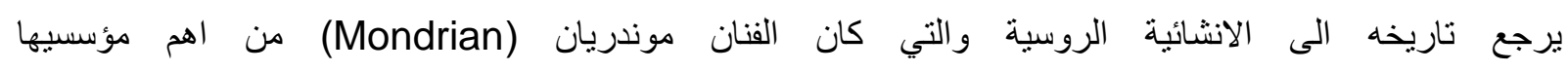
ويرتبط بالنز عة التشكيلية (Formalism) كأساس لبناء العمل الفني هدفها الاختز ال و الرجوع للأسس الجو هرية للأشكال

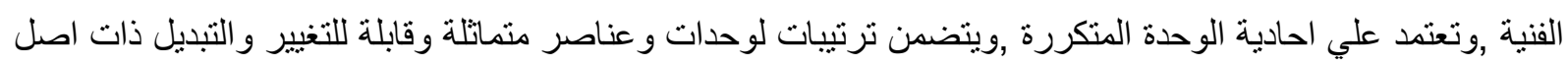

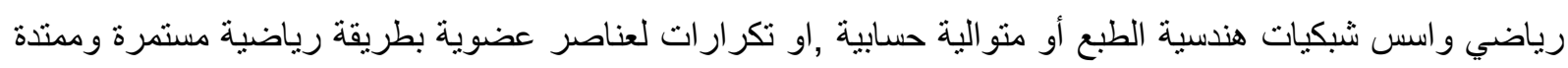
الي ما لانهاية . وتعتبر الملابس ومكملاتها من الحاجات الاساسيه للفرد التى لايمكن الاستغناء عنها فمنذ بداية الحضار ات حاول الانسان

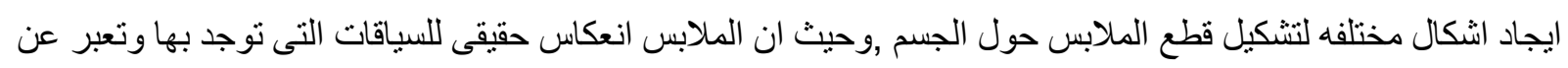
و اقع المجتمعات وتعكس شخصية الفرد . .

\section{• • مشكله البحث(Statement of the Problem):}

تصميم طباعة أقمشة مكملات الملابس تحتفظ ببعض الأنماط الفنية و الحلول التقليدية ,لذا يتجه البحث إلى التجريب من خلال تطبيق الفن الاختز الي للتوصل الى قيم طباعية بغرض طرح رؤية تتكلية جديدة تثرى مكملات الملابس ومن هنا يمكن صياغة مشكلة البحث فى التساؤل الاتى: كيف يمكن الأستفادة من بعض أعمال الفنانين الاختز اليين لتقديم أنماط جديدة من التصميمات الطباعيه لمكملات الملابس ؟ •

1- المساهمة في النعرف على الفن الاختز الي(Minimal Art). 2- ابتكار تصميمات مستوحاه من فلسفة وفكر الفن الاختز الي تتناسب مع الاذواق المختلفة 
3- اثراء وتطوير التصميمات الطباعية لأقشة المكملات من خلال استخدام احدى الثقنيات الحديثة للطباعة 4- الاهتمام باثر اء المكتبة العربية بدر اسة متخصصة جديدة تربط بين الفن الاختز الي وتفعيل استحداث نظم للتصميمات

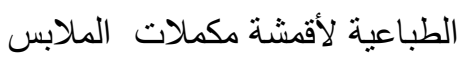
: • الكثف عن مفهوم وسمات القيم التشكيلية والجمالية لمختار ات من اعمال فناني الفن الاختز الي من حيث نوظيف الاشكال

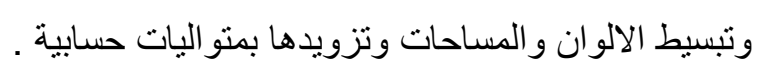

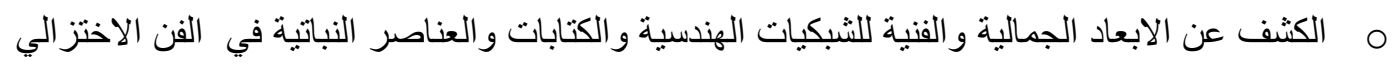

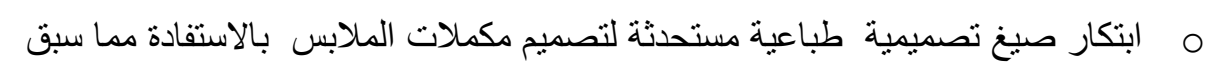
م تحسين الذوق العام للتصميمات الطباعية لأقمشة المكملات

• • : بفترض البحث ان م وجود علاقه ذات دلاله ايجابيه بين استخدام الفن الاختز الى وتصميم طباعة اقمشه مكملات الملابس

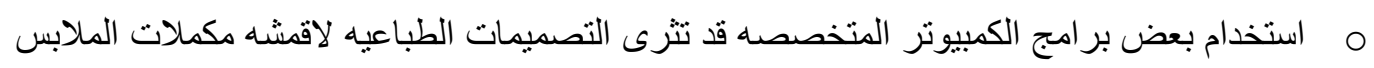

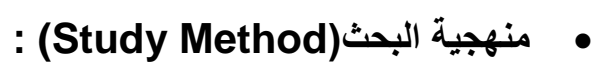
يعتمد البحث في اجر اءاته علي : م المنهج الوصفي: وذلك من خلال الدراسة الوصفية الفلسفية واتجاه الفن الاختز الي . .

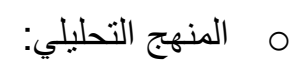
من خلال التحليل الفني لبعض أعمال فناني الاتجاه الاختز الي .

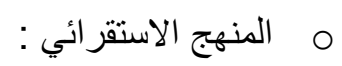
من خلال ادوات المنهج الاستقر ائي التي ترصد اتجاه الفن الاختز الي لتطبيقة على تصميم طباعة أقششة مكملات الملابس.

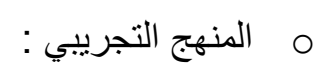
تعتمد عليه الدر اسات في تناول الجانب الابتكاري و التجريبي في تصميم أقشة المكملات o

• حدود البحث (StudyDelimitations): O حدود زمانية :بداية ظهور الفن الاختز الي كاتجاه منذ 1965حتى الان .

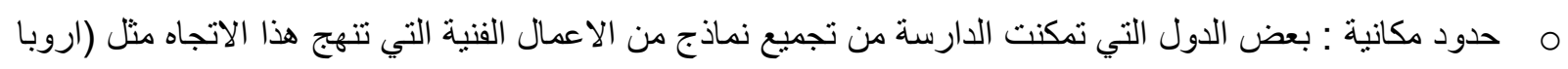

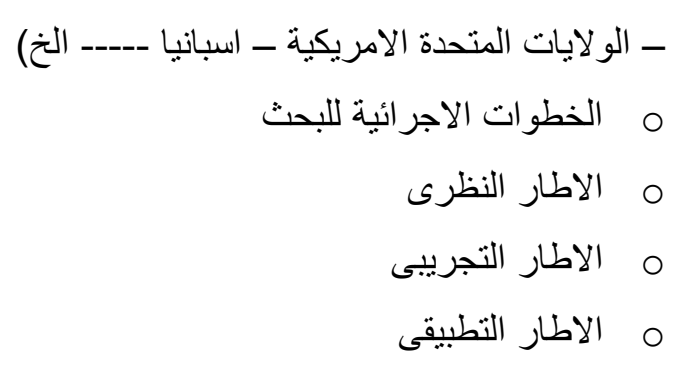




\section{اولا:الاطار النظرى(Theoretical Frameworkh) :}

فن الاختزال او ما يعرف "المنمال"(Minimal Art) هو اتجاه في الفنون والعمارة والادب ومجالات الفنون المرئية

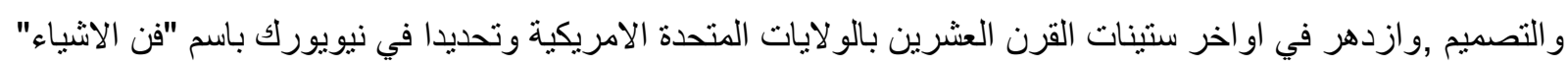
"Object Art " التشكيل ودل في التعبير و استبعاد ما دون ذلك .و هذا النوع من العمل يرجع تاريخه الى الانشائية الروسية والتي كان الفنان

$$
\begin{aligned}
& \text { موندريان Mondrian) من اهم مؤسسيها } 5 \text {. }
\end{aligned}
$$

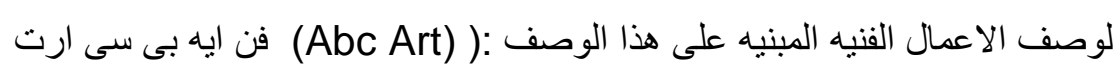

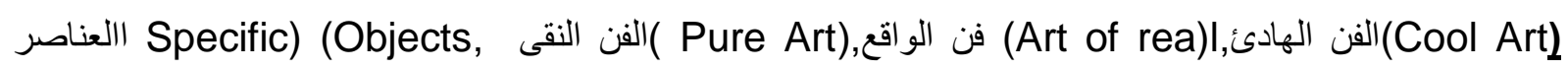
المتخصصة,(Primary Structures) البنية الاولية واول من ادخل مصطلح الختز الية هو الفنان الروسى جون جر اهام) (John Graham في كتاب له بعنوان النظام والجدل في الفن ,نشرة عام 1973 في باريس وقد هدف الى تجريد اللوحهد

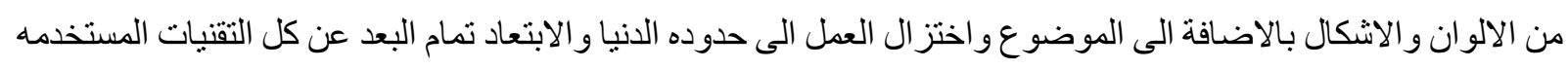

في التعبير التجريدى 14

ويعتبر المذهب الاختز الى من اكثر الحركات الفنية التى تستهدف التكامل التام و النقاء الكامل رواختزال الفن الى ماهو

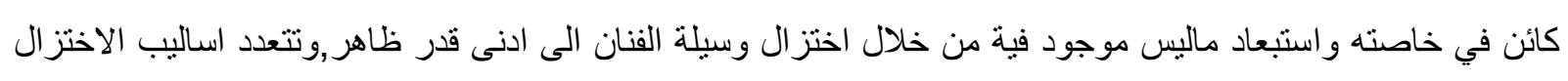

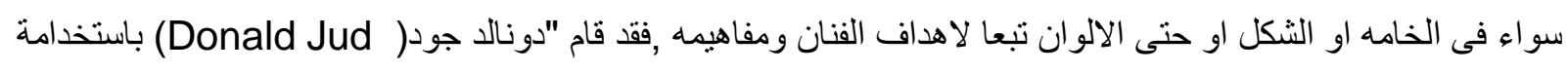
لدعم ماكان يعتقد انه فن مجسم اصيل وجديد ووظهرت في صناديق او مكعبات صناعية ,ووضع بلاط الارضيات ومصابيح النيون جنبا الى جنب ,و انتشرت الثبكات و التركيبات الفر اغيه المفتوحه ,فقد اتسمت اعمال المذهب الاختز الى بالبساطه ولا تقيد بالتفاصيل التى تبعدنا عن الفكرة الاساسية ,مثل مركز الاضاءه و الرؤية .وقد استخدم الخامات سابقه الصنع ذات الاتشكال

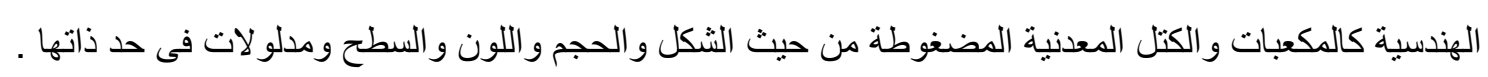

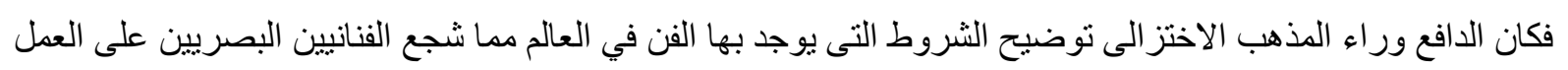
بشكل مستقل فى العديد من البلاد خلال الستينات .

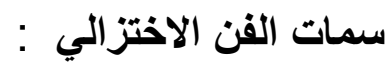

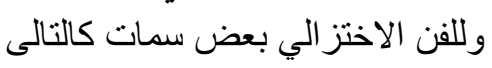

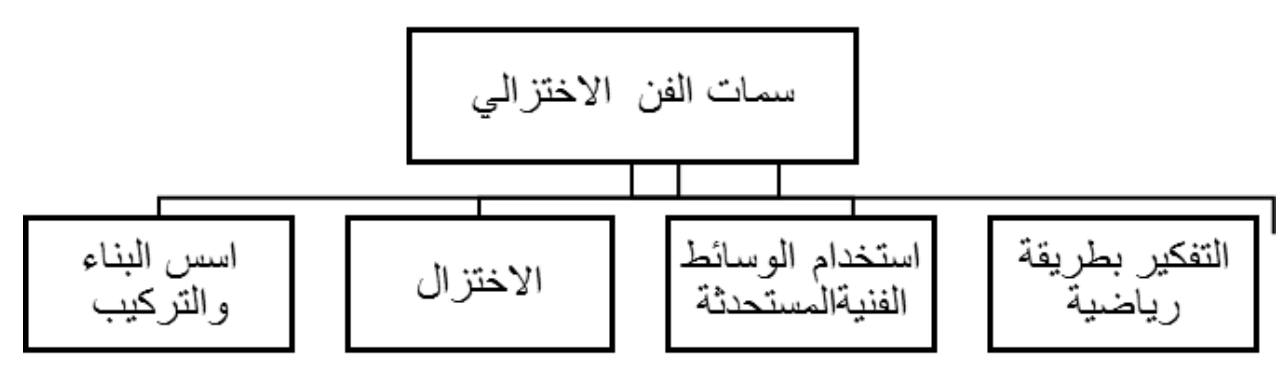

رسم توضيحي(1)

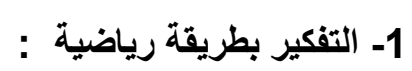

يتشارك فنانى الاختز الية مع فنان البنائيه في التفكير بطريقه رياضية و بمذهب العقلانية (Rationalism) ,وهو ايجاد ابسط صوره من الثكل المعبر عن طريق الايجاز ,وهذا النوع من البساطه بقلل من الاحساس بالفرديه ويقلل من معدل 
الذاتية فى استجابة المشاهد للعمل ,وتزيد من درجه و عية بطبيعة الفن ومحتو اه البنائى في تفاعله مع البيئة ,فجمال الثكل

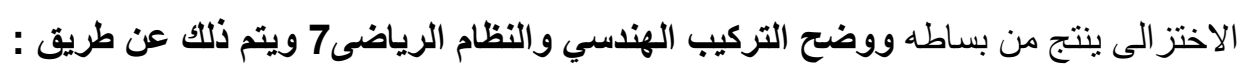
أـ الاعتماد على البنيه الاولية (Primary Structures) وتكرارها وينتمى هذا الاتجاة للاختزاليين الاكثر تشددا ويسطر على هؤل لاء الفنانيين احساس قوى بمعارضة الخداع في الاعمال الفنبة مع التاكيد على التقنية الكاملة في تنفيذ العمل ودقتة9 ,وتتمتع بعض الاعمال بوجود اهتمامات معرفية مثل: خصائص بعض الخامات ,مقاصد فلسفية,الفزياء,دراسة

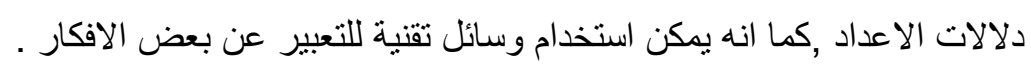
بـ الاعتماد علي استخدام الثبكيات الهندسية (Geometrical Networks )حيث يتم تحقيق مفاهيم حديثه تميل الى ولى عمل اشكال مجردة من الزخرفة ومختزلة الى اقصى حدودها رما يؤدى الى تشكيل عمل فنى بعيد تمام البعد عن الثكل المألوف ,يسعى الى التعبير عن قيم فنية وجمالية مختلفه تعكس افكار الاختز الية الفلسفية

2- 2 استخدام الوسائط الفنية: استخدام الوسائط التقنية للتعبير عن فكره معينه , الي وسيط فكرى وبنائى واصبح الفنان قادر على الخامات التقلدية بالاضافه الى التقتيات المستحدثة والاكثر تطورا فى مفهومها الاستخدامى والبنائى ,وقد لجاء الفنان الاختز الي الى استخدام وسائط طبيعية مثل الخشب و الرمال و النحاس و الحديد ووسائط صناعية مثل البلاستيك والصاج المجلفن ولمبات الفلورسنت

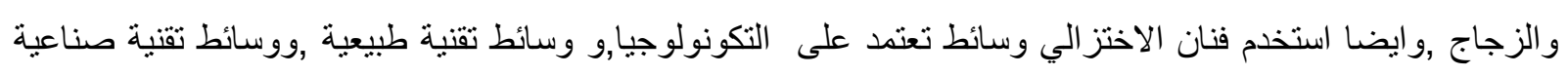

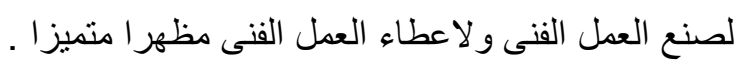

3- الاختزال:

المبدا الاساسى للفن الاختزالى هو ممارسه كافه اساليب الاختزال سواء في الثكل او اللون او الخامة ,وكلمة اختزال

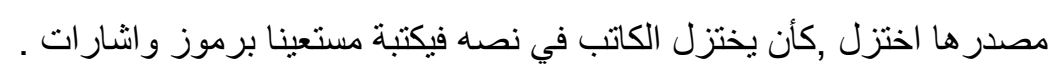

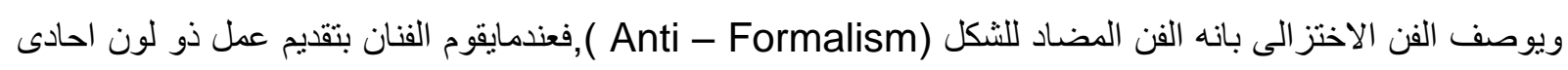
كاللون الاسود فانه لايهدف الى تقديم تصوير ا اسود بل يهدف الى ابراز قيمه الخامة في سبيل نفى قيمه اللون 10. كما ان الاختزال "هو التفكير في الجو هر الحقيقى للاشياء و العناصر من خلال اعادة بناء دلالاتها بعد ان تم اختزال عناصره

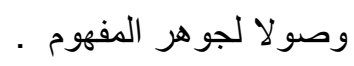
لذلك اهتم الفنان الاختز الى بان يقام الثكل كوحدة واحدة حتى يمكن ادر اكها بكل بساطة ,وتاثير الكل يعطى احساسا بالوحدة

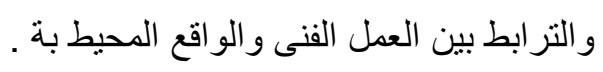
و التفسير الوحيد للجوء الفنان الاختز الى لاستخدام الخامات الصناعية والتكنولوجية في تقديم عملة الفنى حتى يفصل العمل الفنى عن تفاعلات الفنان الثخصية كما يمكن ان يقتصر العمل على خامة واحده حتى لاتؤثر مادة العمل في عرض فئن فكره العمل اى"فصل طاقة الفن عن حرفة انتاج الفن "

4- اسس البناء والتركيب : يرتبط الفن الاختزالي بالنزعه التشكيلية (Formalism) كأساس للبناء ويعتمد تركيب الثنكل على اسس معلومه من

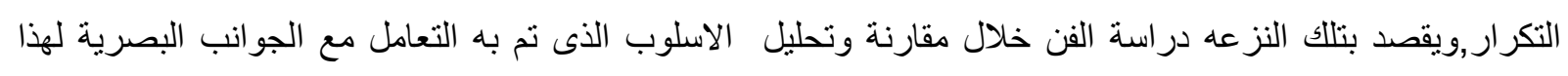

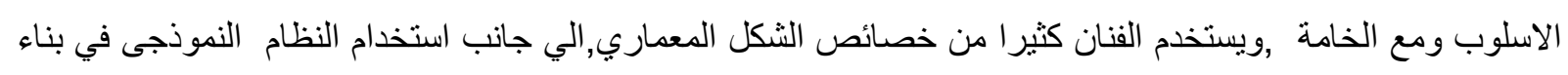
العمل الفنى,لمنع اى قرار لحظى يخضع للنزعات الذاتيه اثناء التنفيذ ومنع اى تنظيم عشوائى. 19 
فهى تركز على الاسلوب المستخدم فى عرض الفكرة من وراء العمل وترفض تماما فكرة التاثيرات الاجتماعية المطبقه علي العمل او التاثير ات الحضارية حيث ان فكره العمل الفني هو اختزال وحذف صفاته الرفيعه والظاهرة ,و يتضمن ترتيبات بسيطه لوحدات وعناصر ها متماتلة وقابلة للتغير ذات اصل رياضى واسس شبكيات هندسية الطابع اوتكرارات عناصر ها يمكن استمر ارها او امتدادها الى مالانهاية . وبناء على ماسبق فان من اهم الصعوبات التى واجهت الفنان الاختز الى هى كيفية اختبار الاشكال او العناصر الفنية التى تساهم فى ادر الك الشعور الذاتى.

\section{اثر الفن الاختز الى علي تصميم طباعة المنسوجات :}

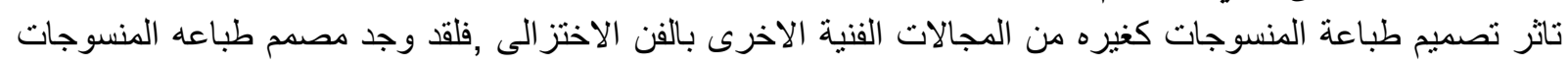

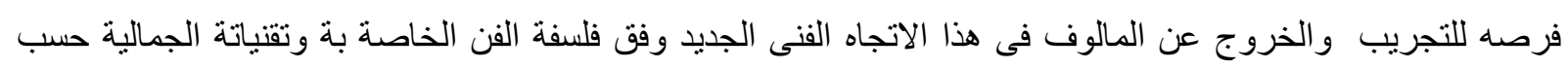
مايتو افق مع اسلوبة في التعبير ,مما ادى الى اكتساب تصميم طباعة المنسوجات فكر ا جديدا يختلف عن كافه الافكار السابقة وبدات الاشكال التصميمة تميل الى التجديد لتحقق قيم فنية وجمالية ومن اهم سمات التصميمات الطباعية ذات الاتجاة

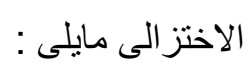

ـ الاختز ال في الثُكل و اللون و الخامة حنى لاتؤثر ماده العمل على فكرة العمل ,و الاعتماد على وضوح الثكل مع ضخامة حجمة. . حست. ـ استخدام الاشكال الهندسية الاولية والاشكال الحرة فى بناء التصميم الطباعى لبعدها عن المعانى الظاهرية والرمزية و الانطباعات الذاتية . ـ اساس العمل الفنى هو الفكرة فلابد من تطويع الماده لصالح الفكرة حتى تظهرها وتوضحها اكثر فاكثر . ـ الاعتماد على الجانب العقلانى و النظريات الرياضية فى التفكير وذلك من خلال استخدام الالوان الاساسية و الاسود و الابيض و الرمادى .

- يتخذ المصمم جميع القرارات بثان انجاز التصميم و الاعداد له مسبقا لمنع اى تنظيم عشو ائى او اتخاذ قرار لحظى يخضع

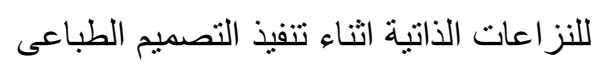
ـ الاعتماد على التقنية الطباعية البسيطه اثناء التنفيذ للحد من التفاعل اللحظى للمصمم مع الخام

\section{بعض تطبيقات اتجاه الفن الاختز الى :}

يعد الفن الاختز الي مرحلة مؤثرة ومهمه فى تاريخ الفن حيث وجد العند العديد من الاعمال الفنية والتشكيلية التى تتسم بالدقة

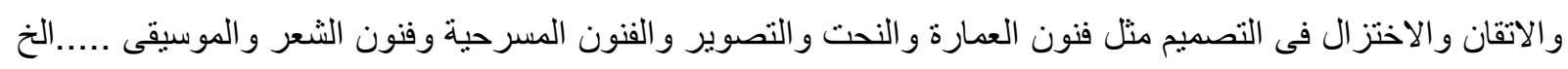

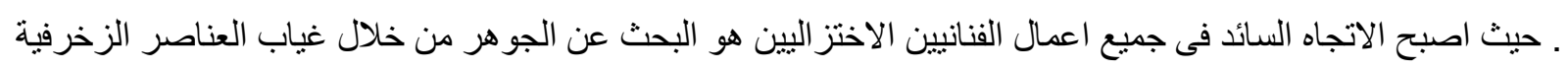

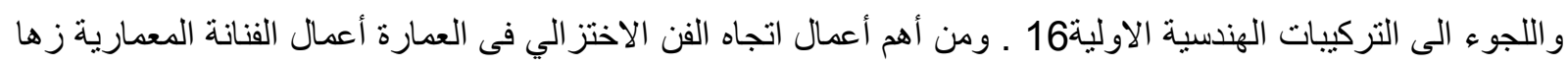
حديد ,حيث ترتبط أعملها بقوة المساحة حيث تمنح البهجة للزائرين بنفس الدرجة التى يمنحها المنظر الطبيعي وتوضيح

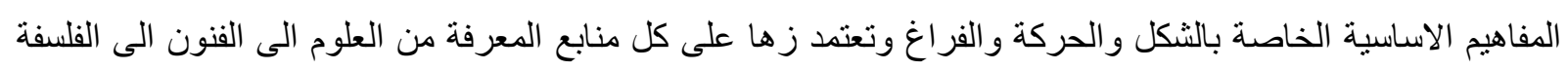
الى الثعر الى الرياضيات و الكمبيوتز ونرفض الى فصل بينهما وتتميز أعمالها بالاختزال مع الحيوية الثنديدة 


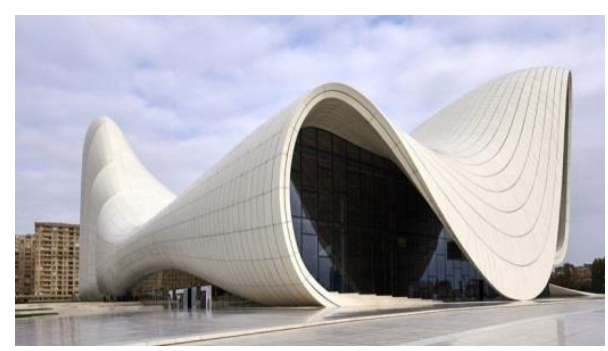

شكل رقم (1) زها حديد

وخير من يمثل المدرسة المصرية فى اتجاه الفن الاختز الي المعمارى الفذ حسن فتحي الذى اتجه الى احياء عمارة محلية

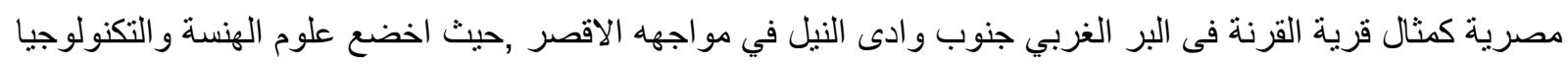

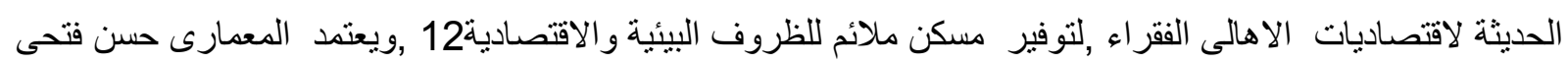

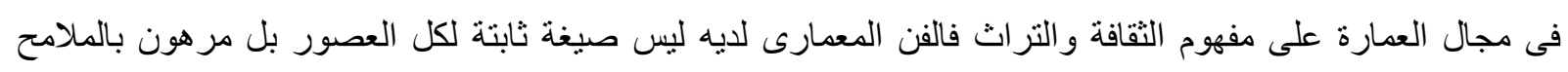

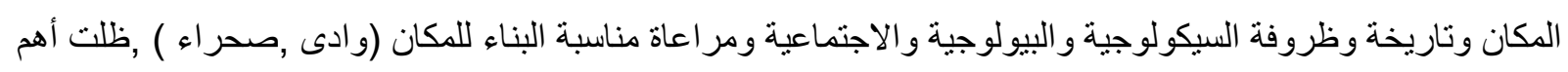
قضية تثغل المعمارى العبقرى حسن هى مشكلة توفير المسكن الصحي الرخيص لأفقر الفقراء من المصريين وربما فقراء

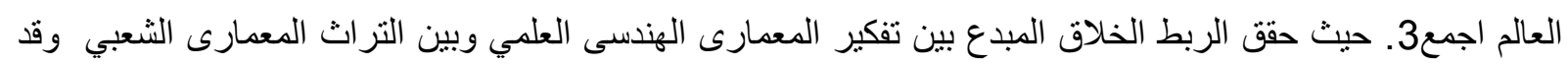

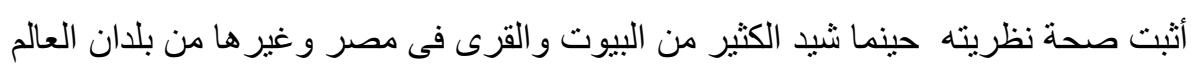

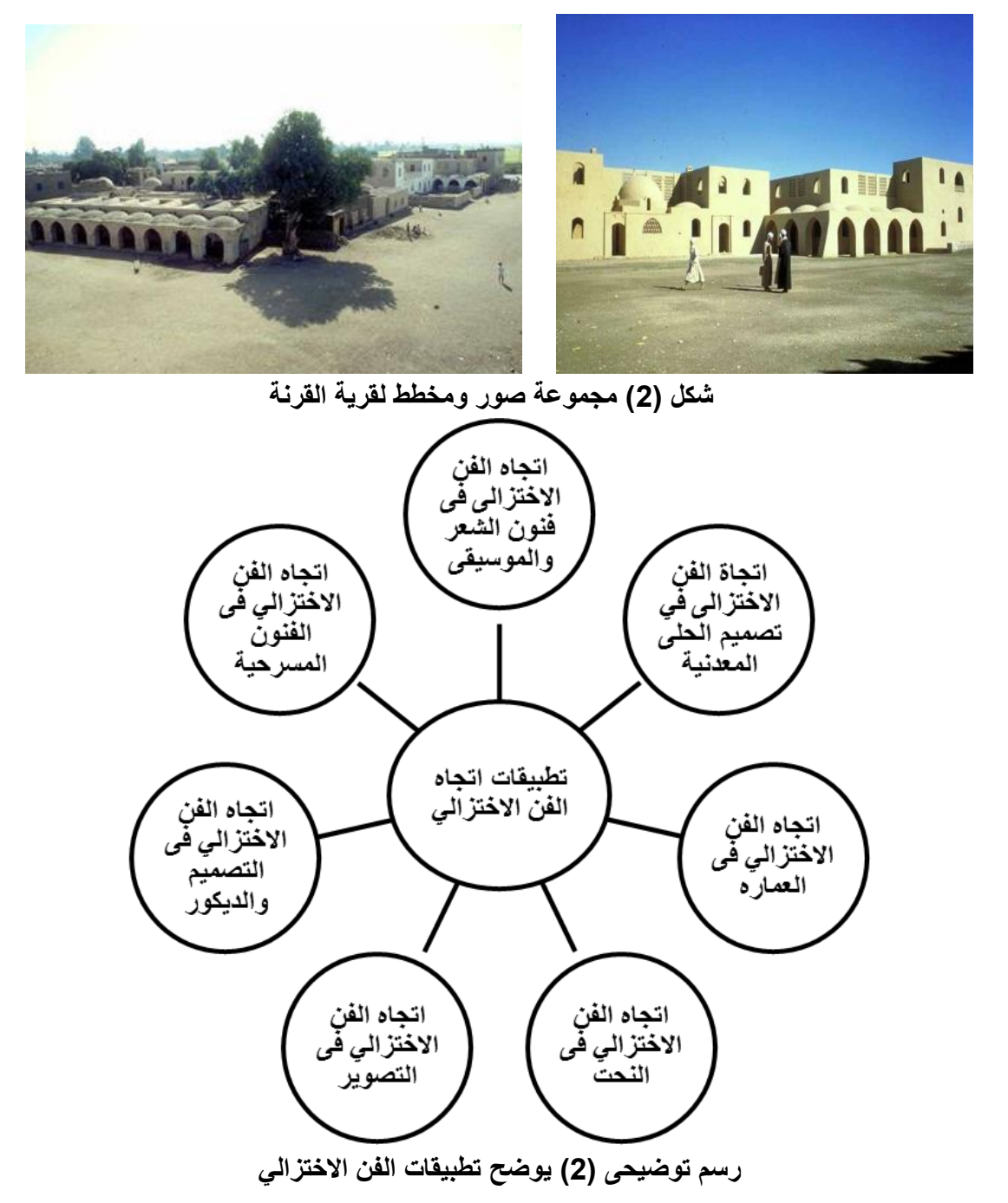




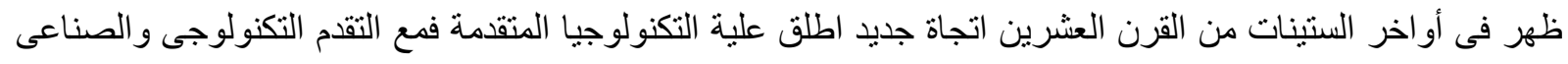

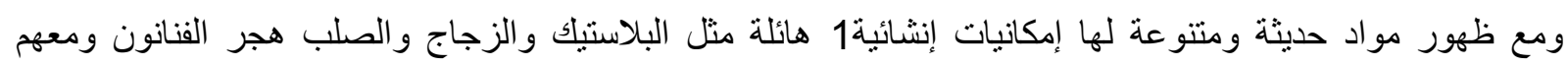

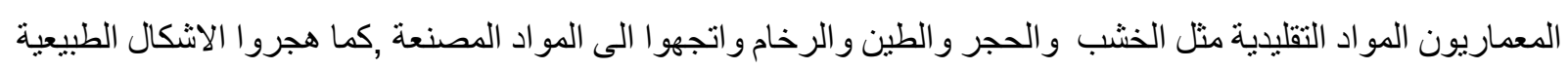

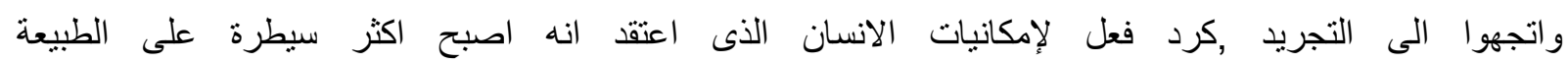

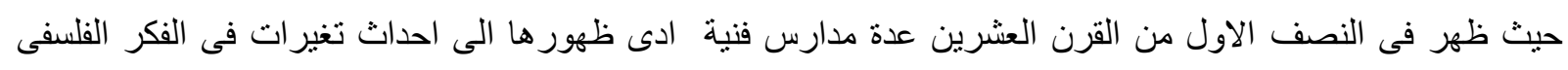

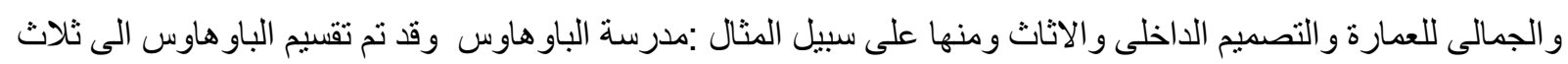

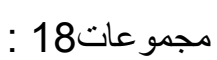

- مجموعة سيام المعمارية (Congrès International d'Architecture Moderne):

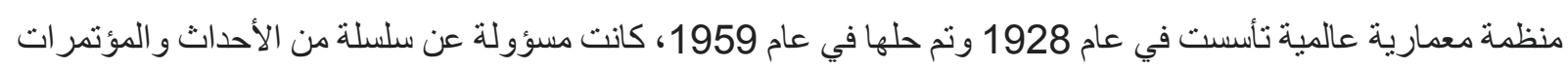

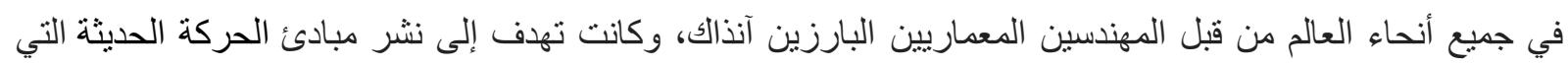

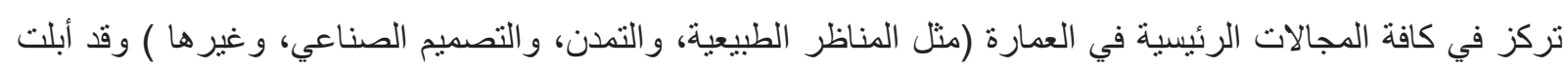
ـ بلاء حسنا مع مشكلة الاسكان وتخطيط المدن .

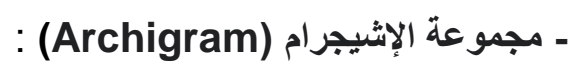

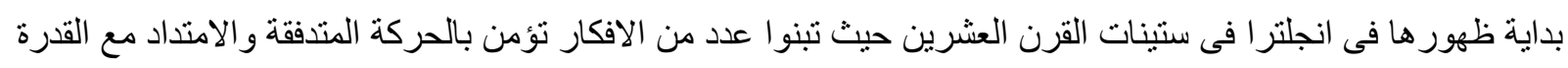

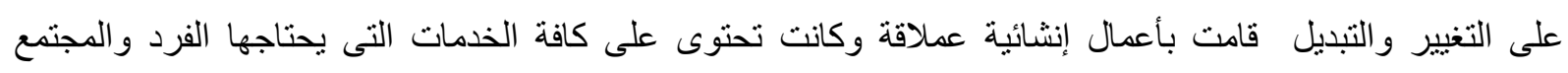

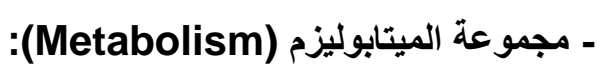
ظهرت فى ستينات من القرن العشرين وهم شباب معمارين يابانيين واتجاهم الفكرى و الفلسفى موجة الى الإنشاء المعمارى

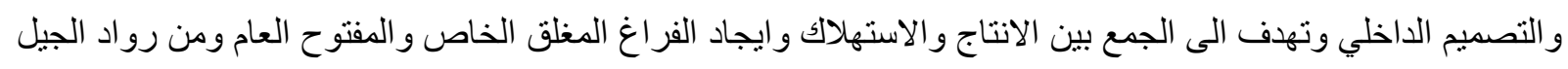

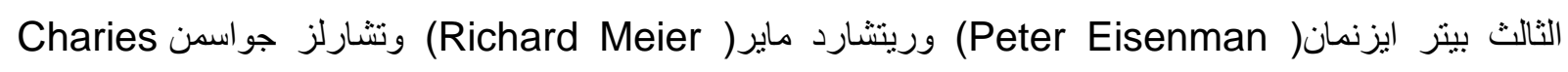
(Gwathmey)

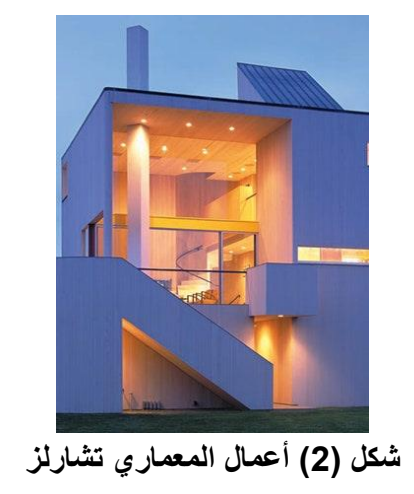

اتجاه الفن الاختزالي فى النحت :

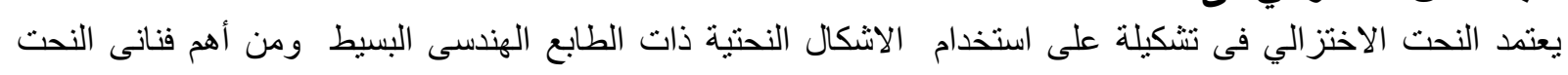

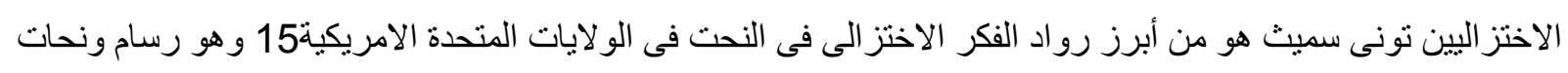

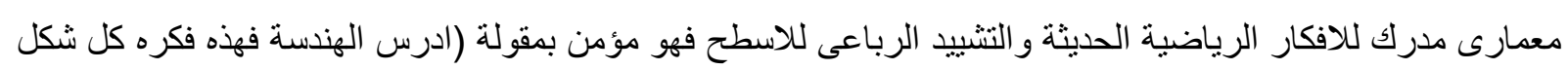

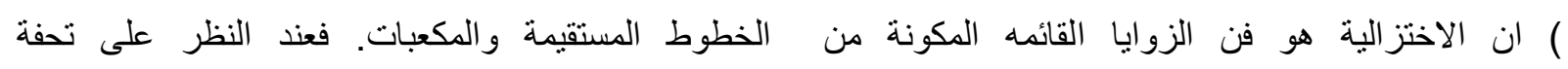


الـsmoke المصنوعة من الالمونيوم الاسود المطلى نجد اهتماة بالثكل الهندسى وبالزوايا و انعكاس الضوء عليها كبقية نحاتى الاختز الية ,حيث الاتجاة الهندسي فى التصميم هو الهدف الاساسى ليصل لأعلى درجة من الدقة الرياضية والهندسية

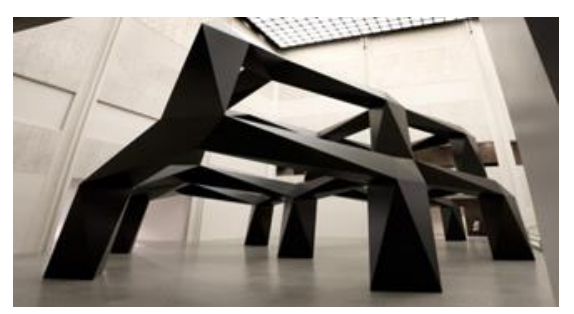

شكل (3) تونى سميث 1967 Smoke

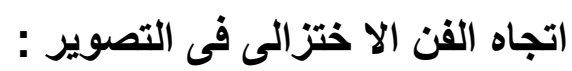

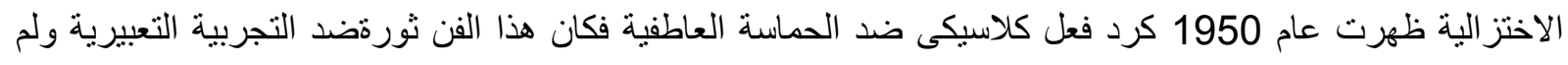

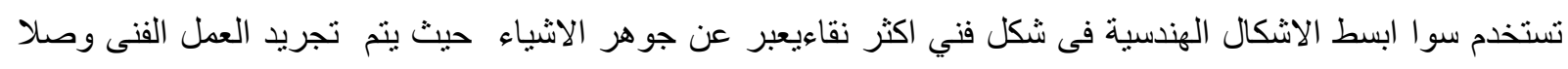

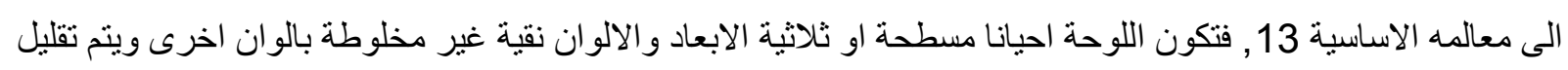
وسائل التعبير وتقنية الاشكال

ويتضح ذلك فى اعمال الفنان روبرت روانثبرج (ropert rauschenberg) فى الخمسينات فى اعماله المسماه

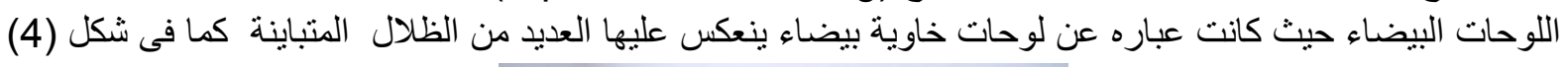

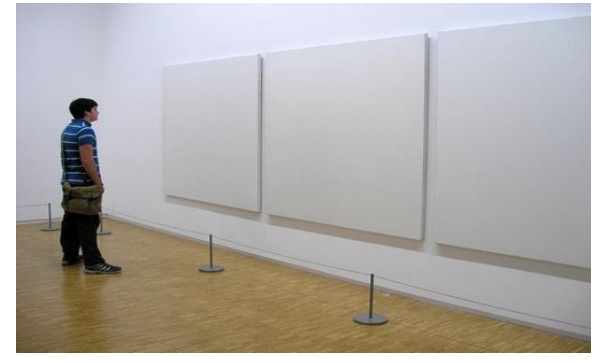

شكل ropert Rauschenberg(4)

اتجاه الفن الاختزالي فى التصميم الاخلى والاثاث :

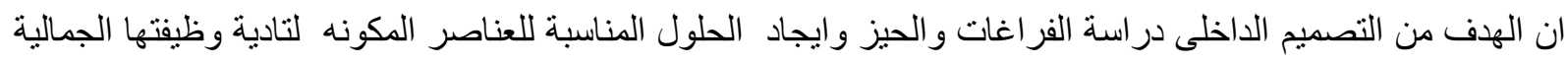

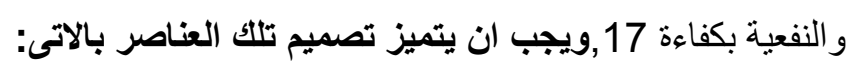
- سهولة الفاك و التركيب و النقل ـ - امكانية الحذف و الاضافة والطيو التخزين

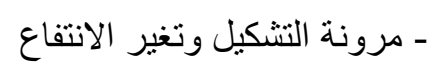

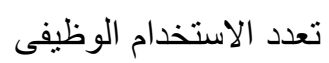

يعد ميس فان درووه من اهم المعماريين الذين اهتموا بالتصميم الداخلي والاثاث ومن اشهر اعمالة واجمالها منزل( تلإل)

(tugendhat 

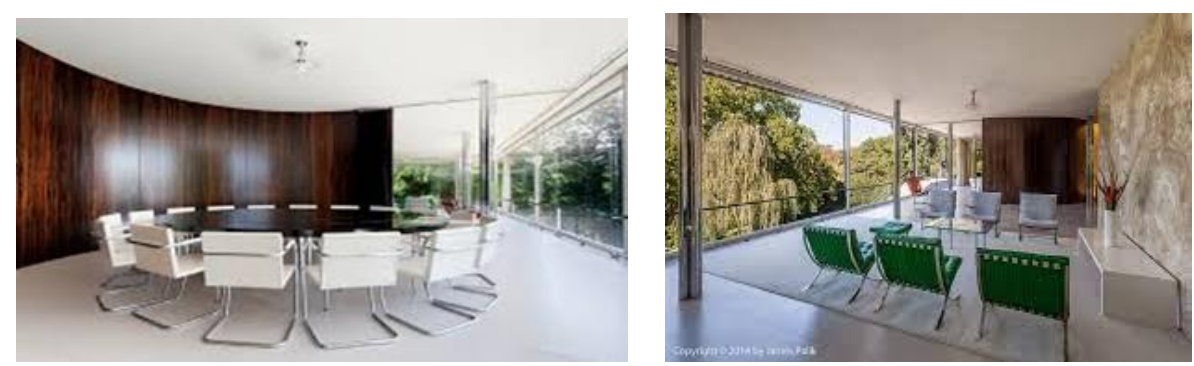

tugendhatt) شكل (5) فيلا

اتجاه الفن الاختز الي فى الفنون المسرحية :

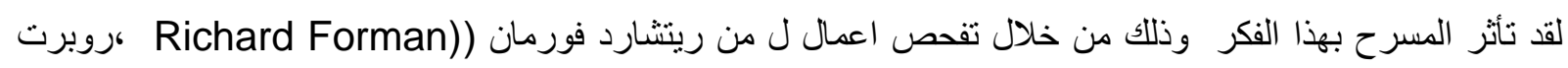
ويسلسون(Robert Wilson) , مايكل كريبى (Michael Kirby)

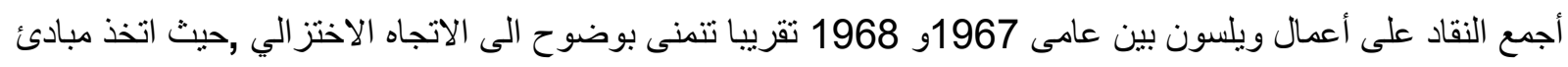

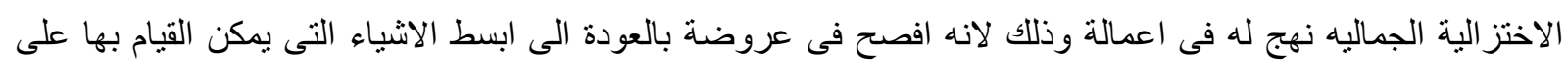
خشبة المسرح وكيفية التصرف على المسرح .
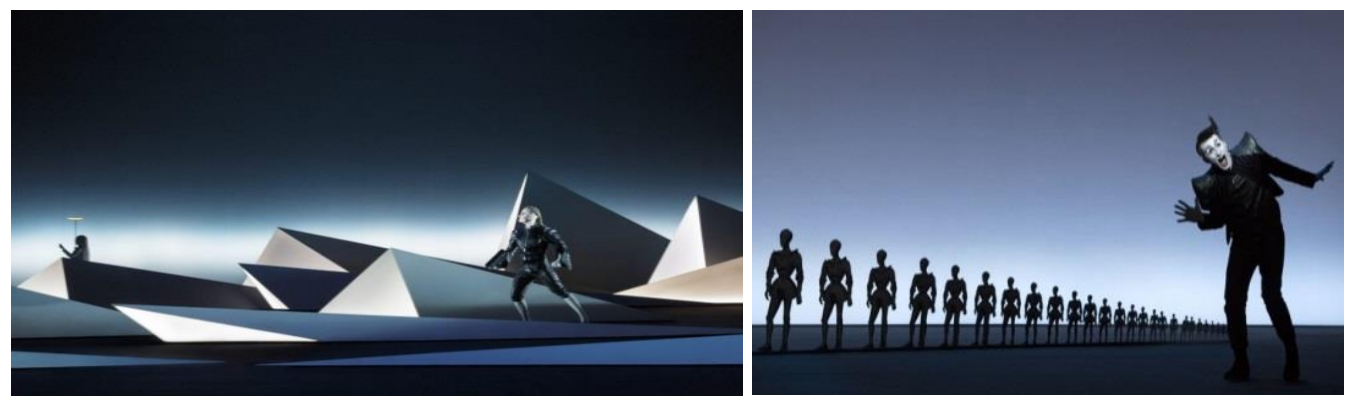

Robert Wilson (6) شكل

اتجاة الفن الاختز الى في تصميم العلى المعدنية

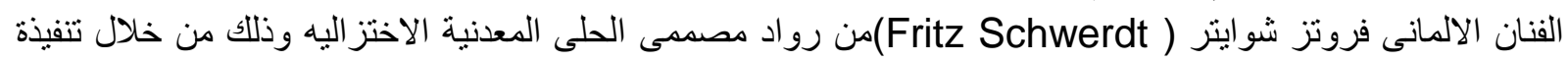
لمجموعة من الحلى تتسم بالبساطة والدقة كما فى شكل (7) حيث استخدم الفضه مع حجر الهيماتيت والعقيق فى شكل

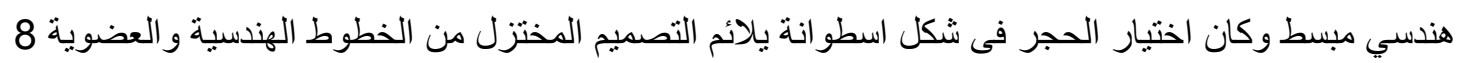

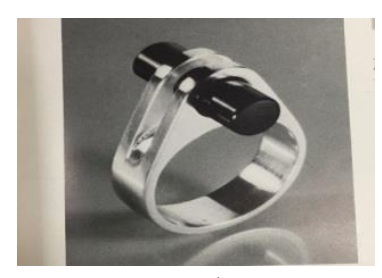

شكل (7)فروتز شواتير

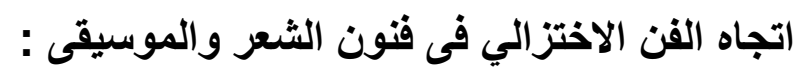

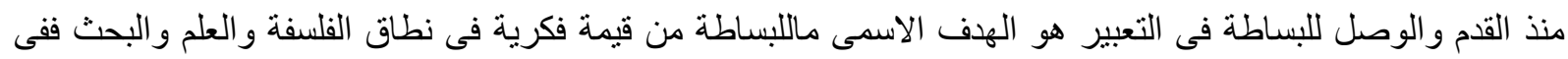

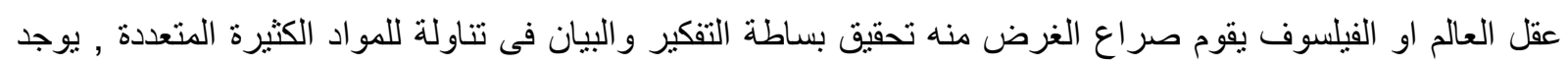

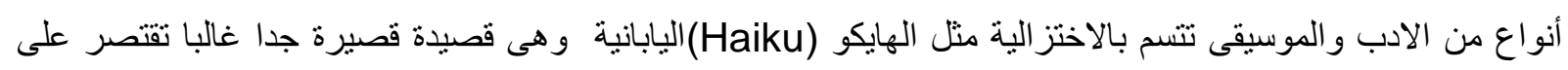

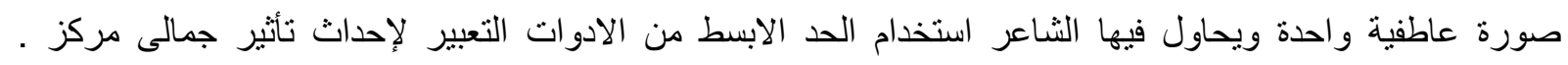


فالاختز ال فى مجال الادب قائم على استخدام العبارات القصيرة التى تظلو من الاساليب البلاغية وفى الموسيقى الاختز ال

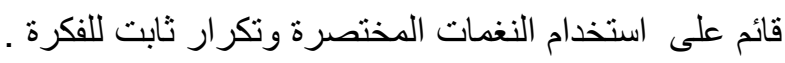

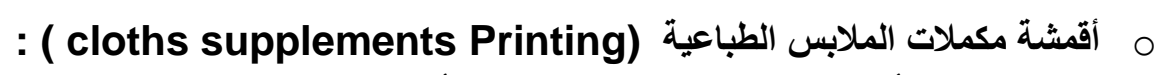

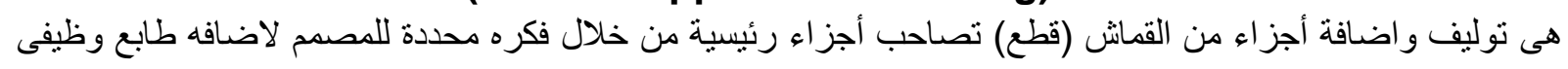

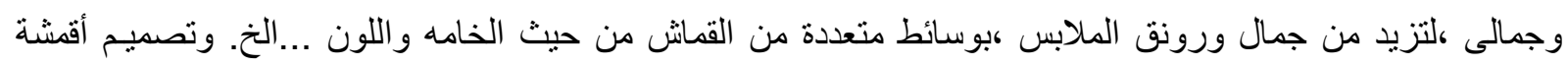

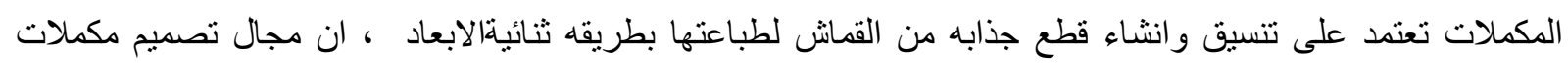

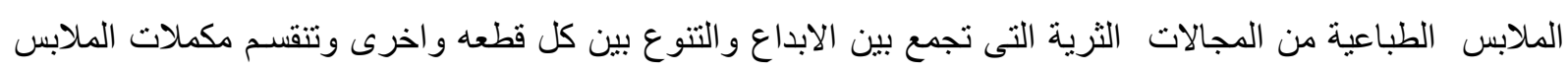

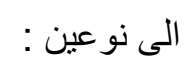

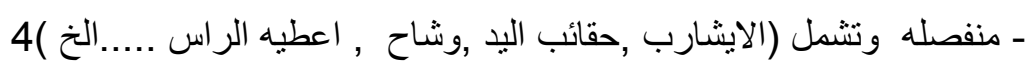

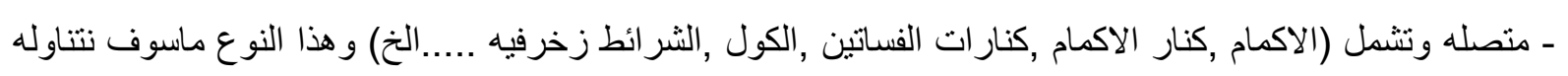
في البحث

م مثانيا : الاطار التجريبي :

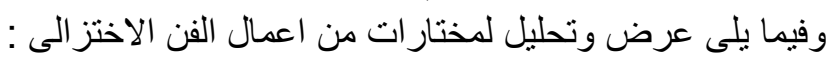

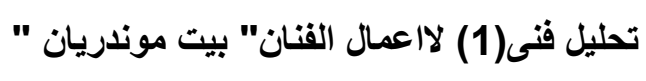

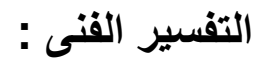

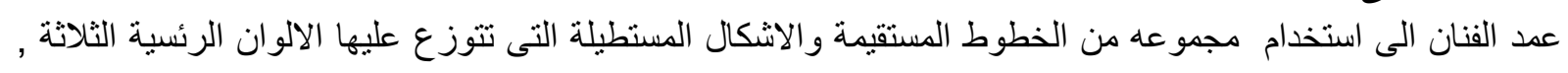

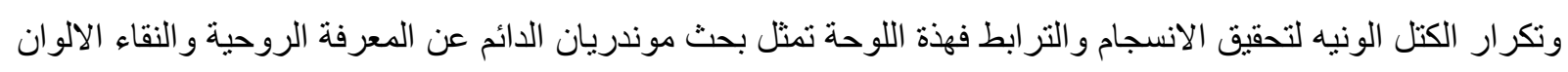
وبساطه التكوين كما قال بعض النقاد وقد كانت ملهمه لكثير من الفنانيين

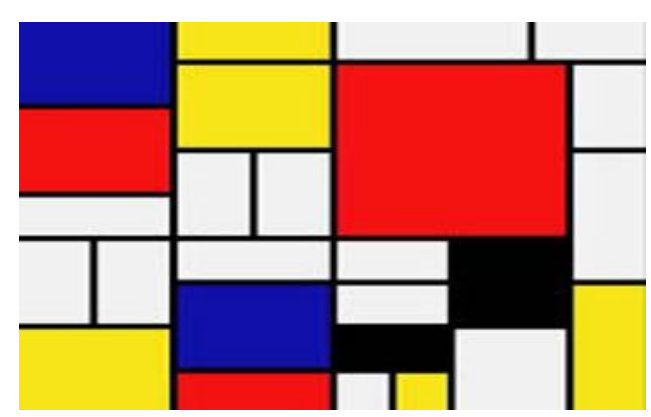

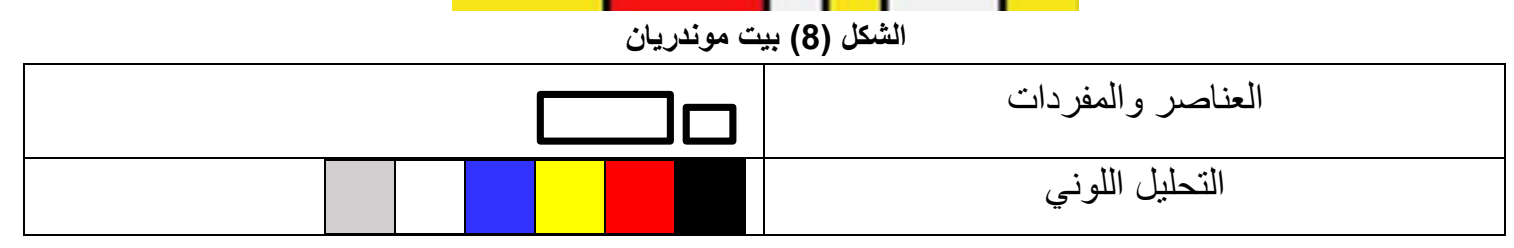

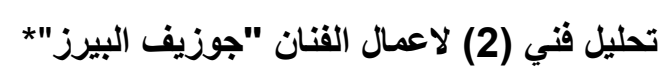

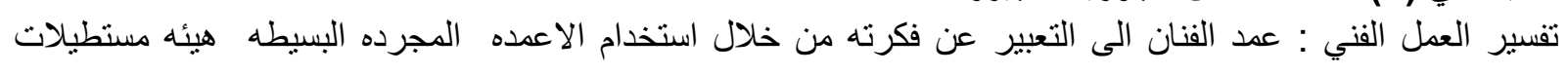

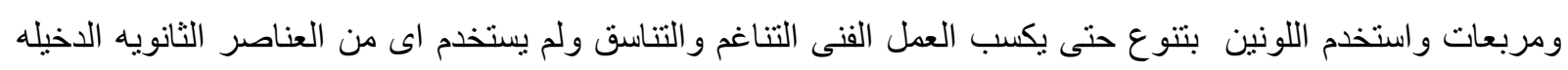
لاكمال العمل الغنى وانما فض التركيز على عناصره الاساسيه لتنبرز جمال العمل ولكل 


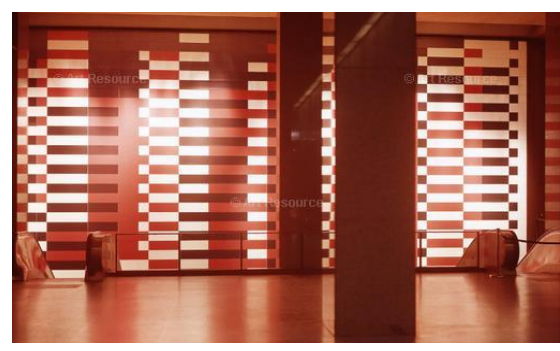

شكل (9) - فن اختزالى- جوزيف

\begin{tabular}{|l|l|l|l|}
\hline \multicolumn{2}{|c|}{} \\
\hline \multicolumn{2}{|c|}{} \\
\hline & & & \\
\hline & & & \\
\hline
\end{tabular}

* تحليل فنى (3) لأعمال الفنان "ادرينهارت "إنئ

التفسير الفنى :اعتمد الفنان للتعبير عن فكرته باستخدام اضاءه النيون و اللون الاسود وشكل هندسي واحد وهو المربع الذى يرمز الى العدل والاستقرار و الكمال والثبات فاللون الاسود يرمز الى المجهول حيث يخلق شعورا بالغموض ويحتفظ

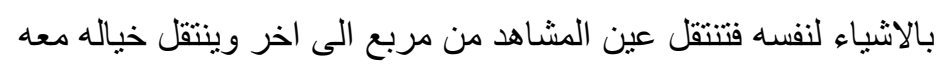

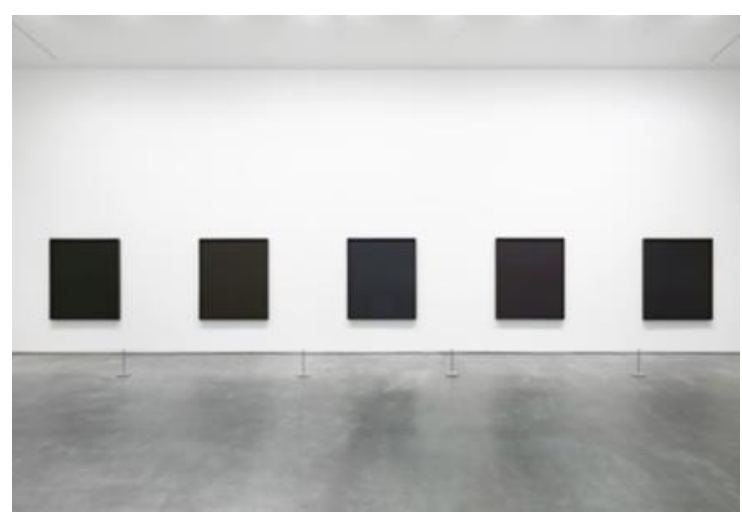

AD Reinhardtتشكل (10) أد راينهار

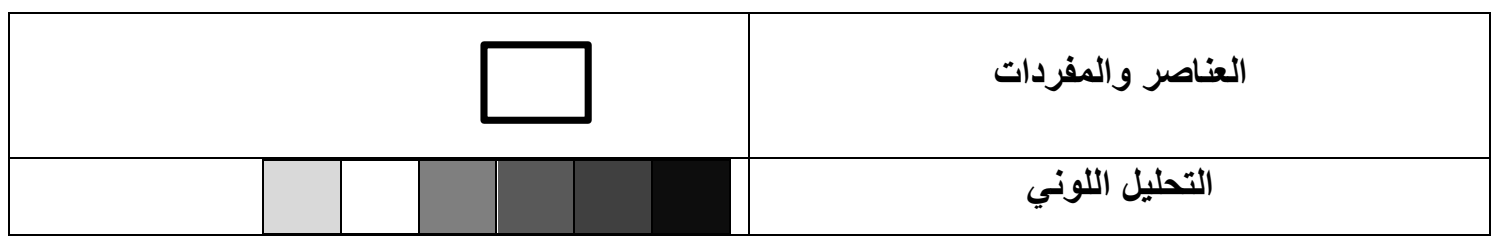

تحليل فني (4) لأعمال الفنان "روبرت ريمان": التفسير الفني:اعتمد الفنان فى التعبير عن فكرته الى استخدام اللون الابيض و التجرد التنام من استخدام ایى انكال لترك خيال

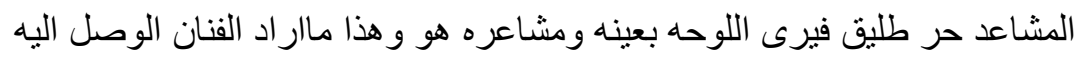




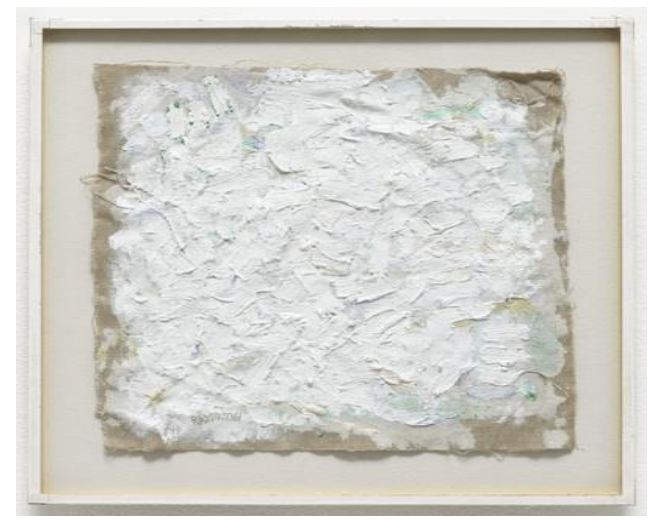

شكل (11) روبرت ريمان

\begin{tabular}{|c|c|}
\hline ملمس لونى بسكينة اللون & العناصر و المفردات \\
\hline & التحليل اللوني \\
\hline
\end{tabular}

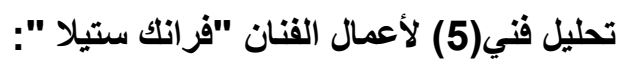

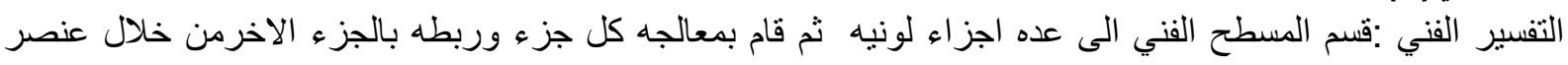

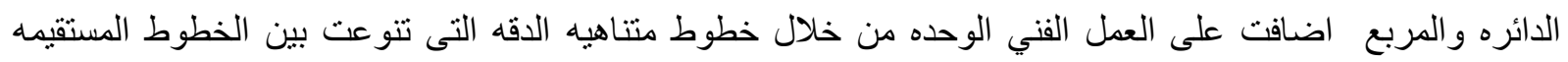
و المنحنيه للتعبير عن الحركه و الكتله مما اكسب العمل الفني نوعا من الدنمايكيه و الثراء الكاء

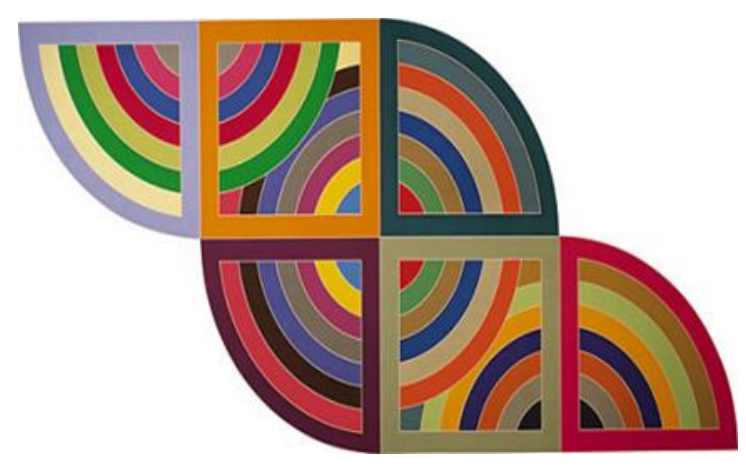

شكل (12) فرانك ستيلا

\begin{tabular}{|l|l|l|}
\hline \multicolumn{2}{|l|}{} & \\
\hline & & \\
\hline & & \\
\hline
\end{tabular}


التفسير الفني : اعتمد الفنان على استخدام العنصر المعدنى للتعبير عن القوه والصلابه كما اعتمد على استخدام الخطوط

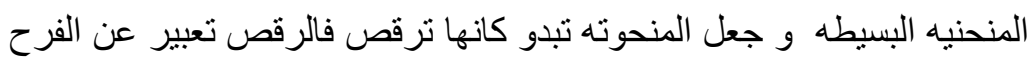

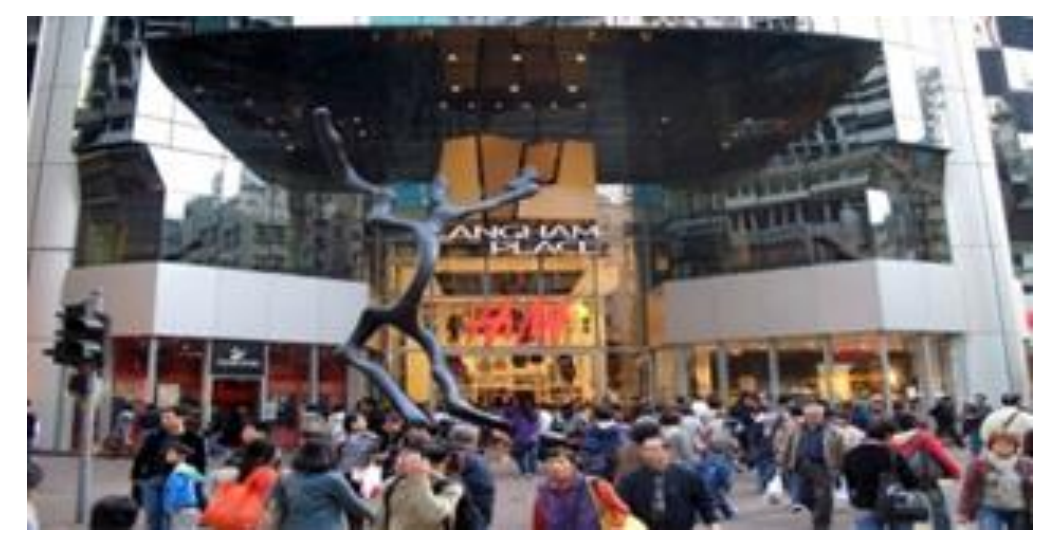

شكل (6) لارى بيل تمثال من البرونز

\begin{tabular}{|l|l|l|l|l|l|}
\hline & & & \\
\hline & & & & \\
\hline
\end{tabular}

الدراسة التجربيه التشكيليه: مكملات الملابس الطباعيه هى جزء ههم من مكملات الاناقه التى تضفي نكهتها الخاصه للملابس وتمنحها اطلاله مميزه،

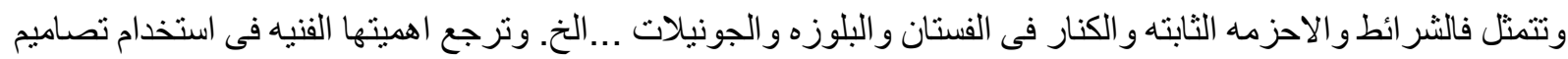

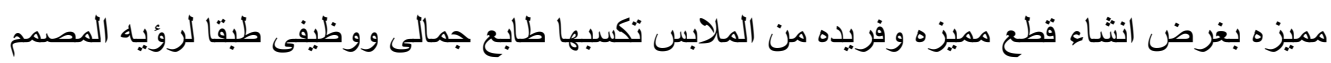
وفيما يلي عرض لبعض التصميمات وتطبيقاتها وتوظيفها:

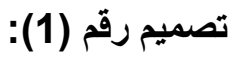

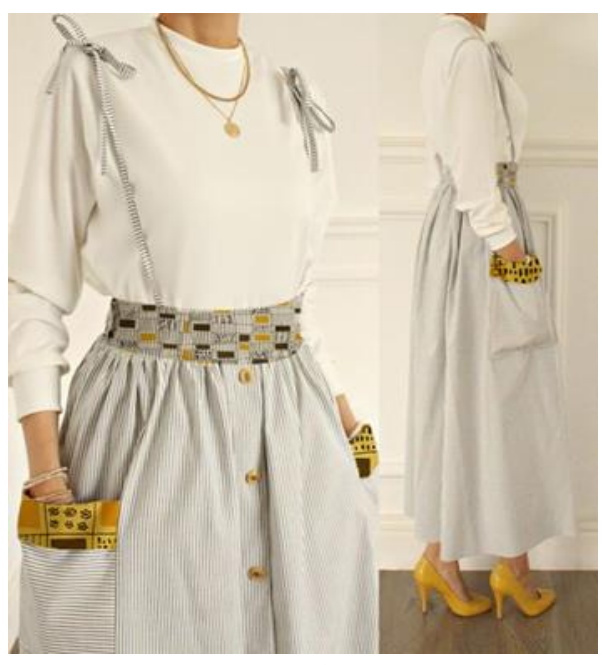

توظيف (1)

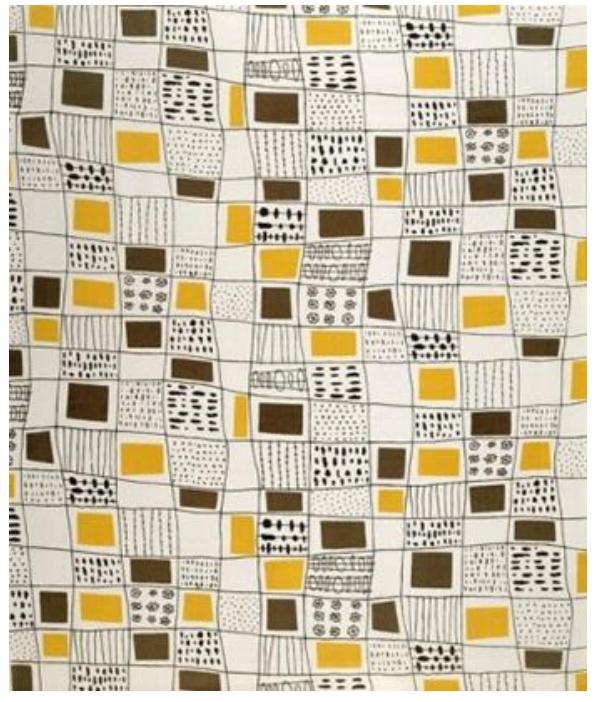

ابعاد التصميم :(1):20×35سم 
مستوحى من :تحليل فنى (1,2)

التحليل الفنى : استخدامت الدراسة الثبكيات الهندسيه فى لوحه بيت موندريان فالفن الاختز الى اساسة الاشكال الهندية

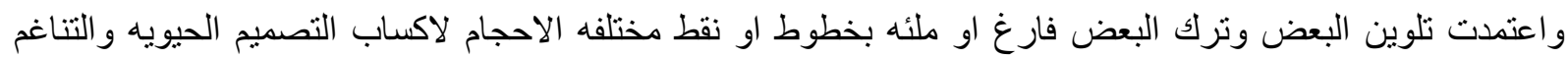
المطلوب واعتمدت عدد قليل من الالوان كما فى لوحات الفنان جوزيف البيرز فالبساطه من اهم سمات الاختز الية .

تصميم رقم (2):

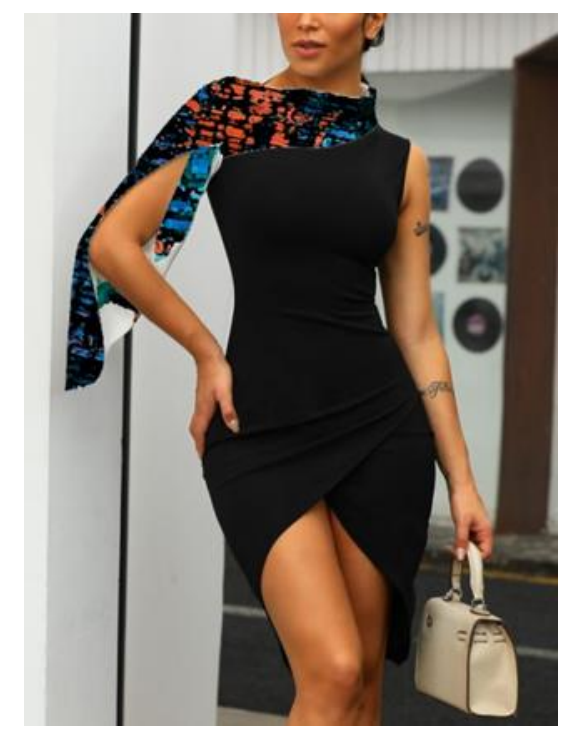

توظيف (2)

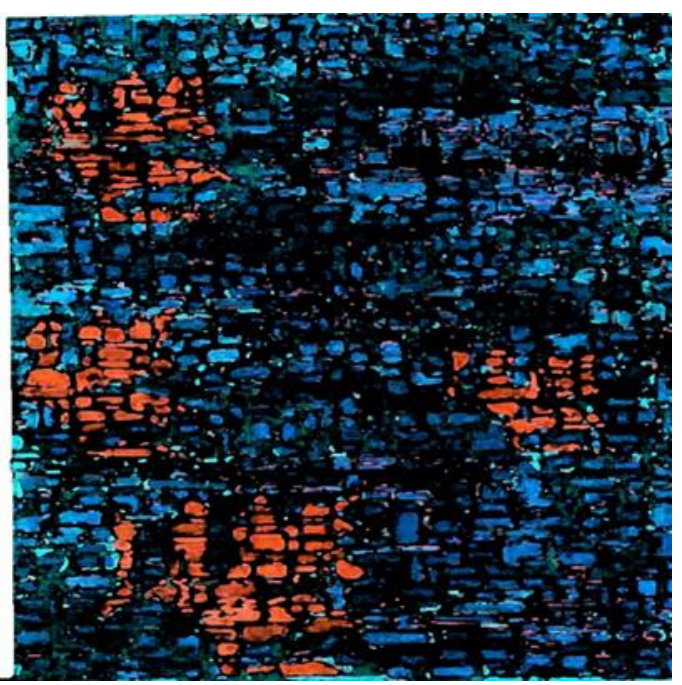

ابعاد التصميم :25*35(2)

مستوحاه من :تحليل فنى رقم (3,4) التحليل الفني: استخدامت الدر اسة المربعات السوداء ل الفنان اد رينهار ات و اضافت لها ملمس لوني لتحقق الحيويه و الحركة

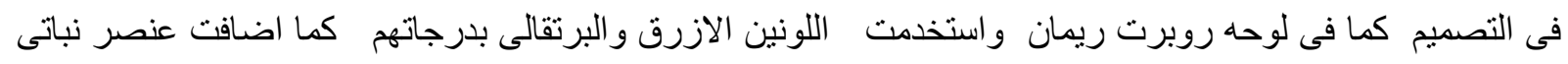

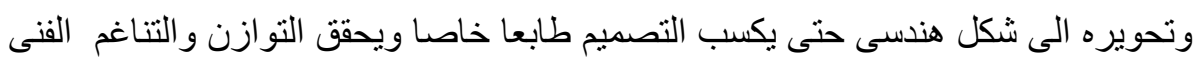
تصميم رقم (3):

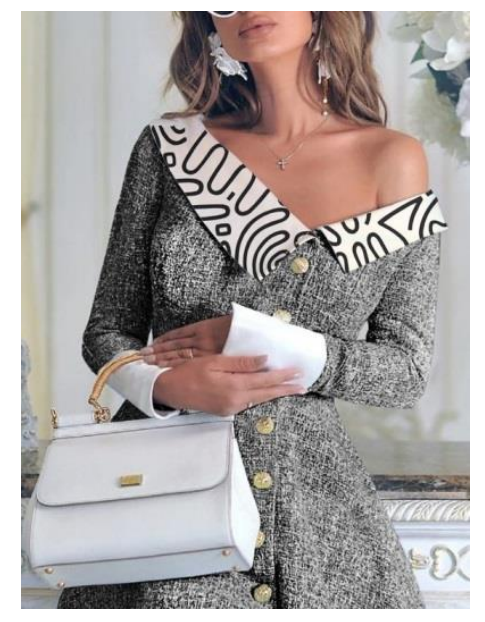

توظيف(3)
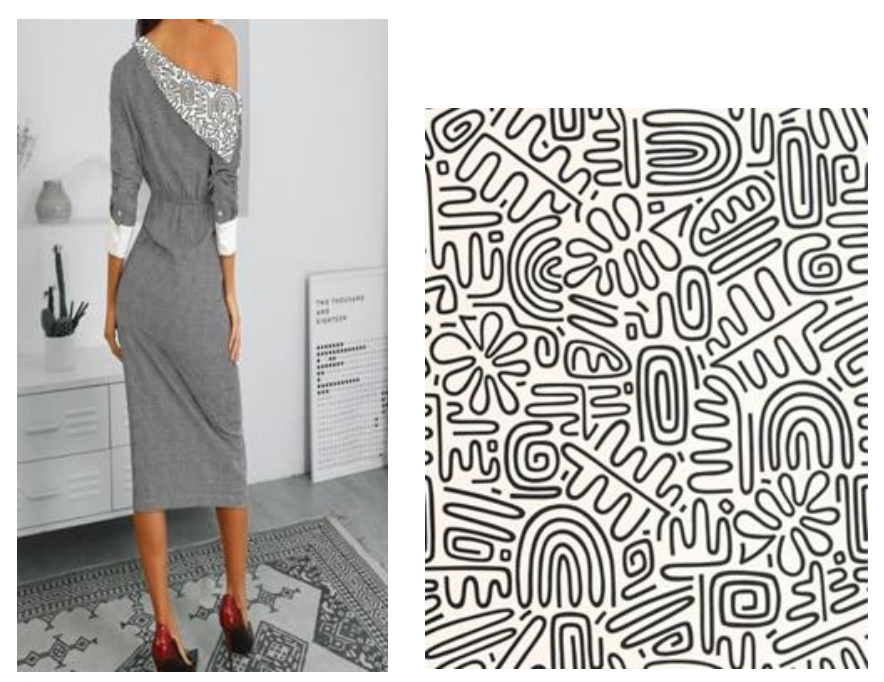

ابعاد التصمي:: (30) 3025سم 
مستوحاه من :تحليل فنى رقم (6)

التحليل الفني : لارى بيل عندما استخدم منوحته الرجل السعيد اعتمد على استخدام الخطوط اللينه المنحنيه لاابراز الحيوية والحركه فمن اهم علامات السعاده هى مدى نشاط الثخص وحيويته كذلك التصميم الحالى اعتمدت الدارسه على ابراز

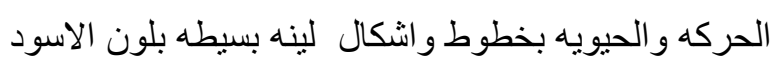

تصميم رقق (4):

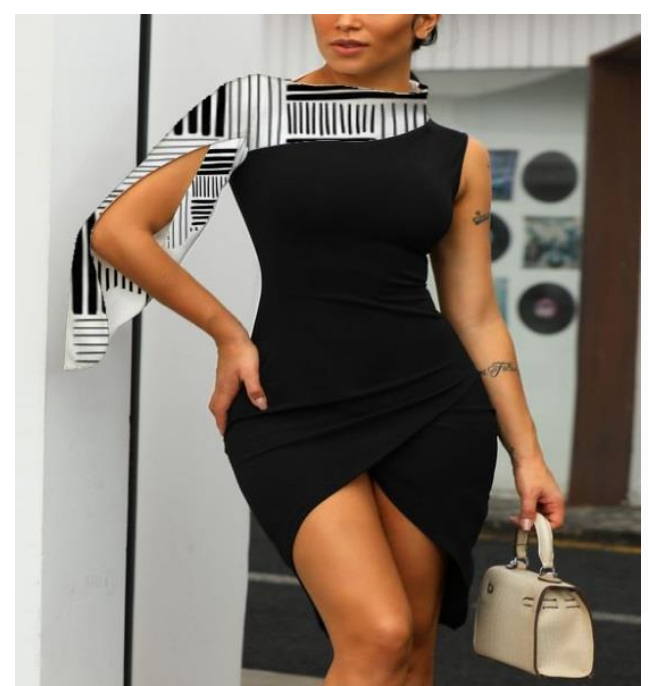

توظيف (4)

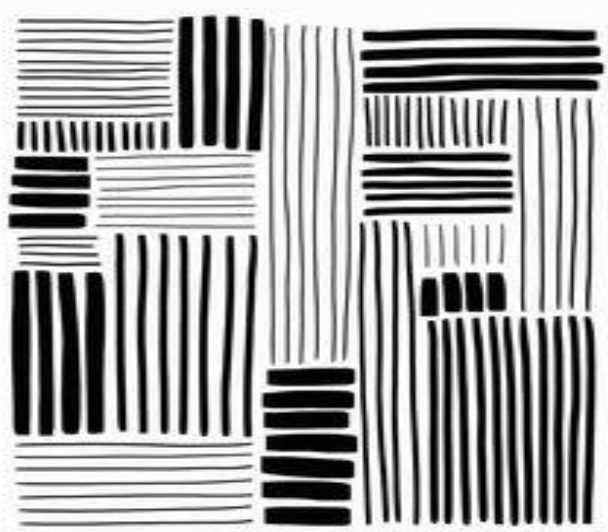

ابعاد التصميم : (4) 20×20سم

مستوحاه من : تحليل فنى رقم (1)

التحليل الفني : عمدت الدراسة الى استخدام شبكية بيت موندريان ولكن بطريقه مختلفه استخدمت فيها الخط بكل ثخناته

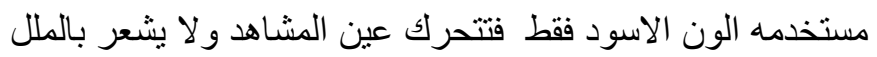

تصميم رقح (5):

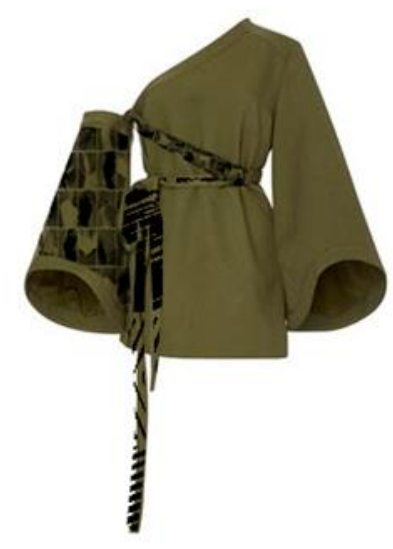

توظيف (5)

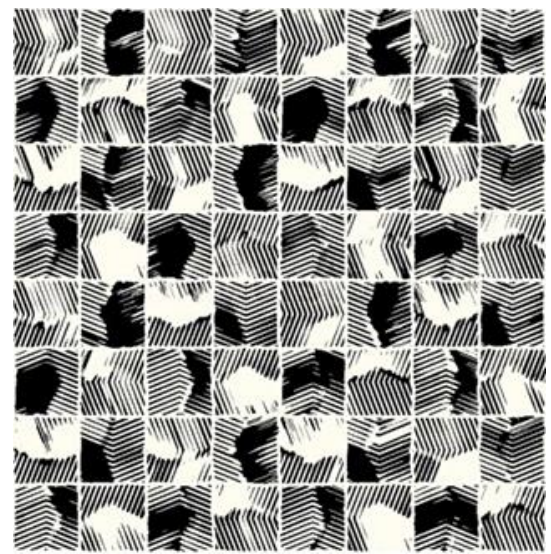

أبعاد التصميم : (5) 25×25سم 
التحليل الفني :استخذت مربعات اد رينهارت السوداء ذات الحجم الواحد والاضاء الماء المنكسره على اعمدة جوزيف البيز

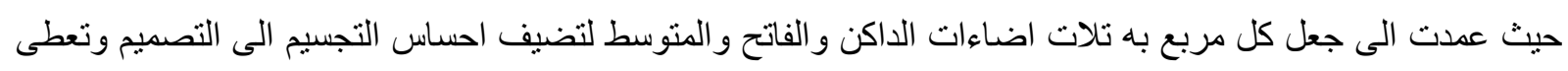

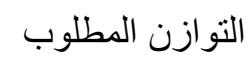

\section{تصميم رقم (6)}

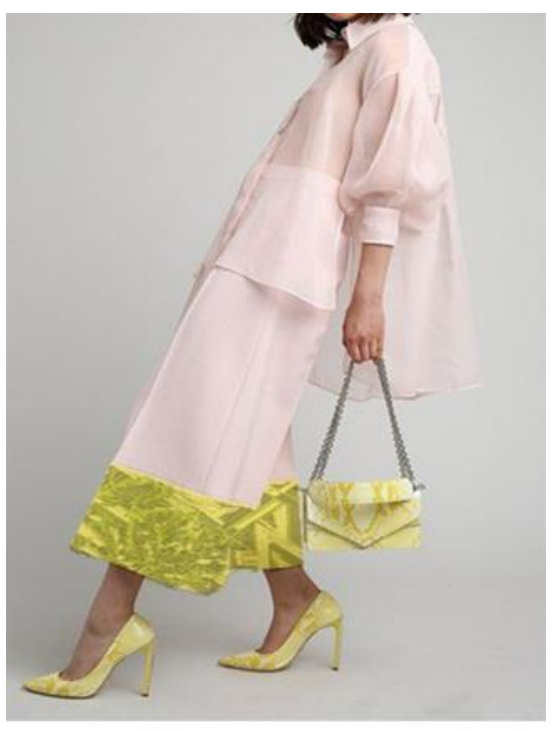

توظيف (6)

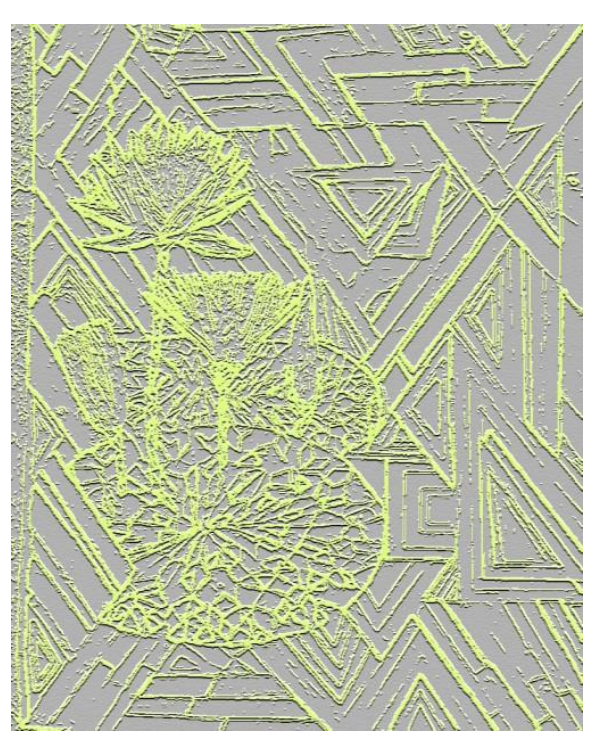

ابعاد التصميم : (6) 35*25سم

مستوحاه من :تحليل فنى رقم (5) التحليل الفني : استخدمت الدر اسة هندسيات فر انك استيلا مع تفريغها من الالوان و واضافت العناف العنصر النباتى وتحويره بطريقه هندسيه واعتمدت على استخدام لون واحد فقط للتصميم لاابر از التفاصيل

\section{النتائج : \\ توصلت الباحثه الى النتائج التالية :} 1- در اسة وتحليل لوحات فنانى الاختز اليه ساهمت بشكل كبير فى تحقيق أبعاد فكرية وفنية جديده تثرى الابداع الفنى لدى الدارسة 2- تخلى فناني الاختز الية عن الاساليب التقليدية التى يجدونها وهم بذلك قد اكتشفو ا واحده من أهم السمات المميزه لهذا الفن. 3- يسم البحث فى اعداد فكر جديد للتصميمات الطباعية بشكل عام ولتصميمات الطباعية لأقمشة المكملات بشكل خاص وهن

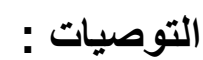
1- ضرورة الاهتمام بدر اسة أعمال فنانى الغرب بوجه عام ودر اسة اعمال فناني الاختز الية بوجه خاص ,لما فى ذلك من

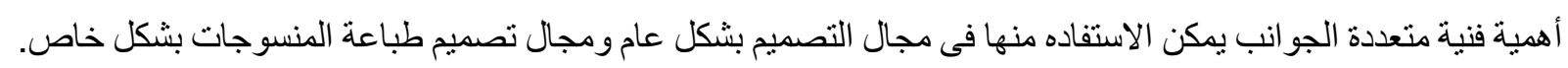
2- الاهتمام بابتكار تصميم أقشة مكملات الملابس الطباعية نظرا لقلة الابحاث والدراسات في المكتبة العربية 3- زيادة الاهتمام باستخدام الحاسب الالي فى مجال التصميم الطباعي وطباعة المنسوجات بصفة عامة 
1- اسماعيل, اسامه حسن :الاختز الية كاتجاه في التصميم الداخلى السكنى (دراسة تطبقية ) مجلة الزرقاء للبحوث

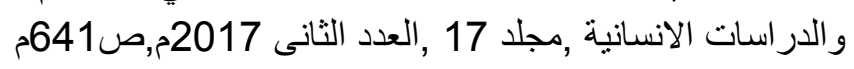

1- asmaeyl, asamh hasan :alaikhtizaliat kaitjah fi altasmim alddakhilaa alsukanaa (drrasat tatbuqiatan ) majalat alzarqa' lilbihawth waldirasat al'iinsaniat, mjald 17 ,aleadad alththanaa $2017 \mathrm{~m}, \mathrm{~s} 641 \mathrm{~m}$

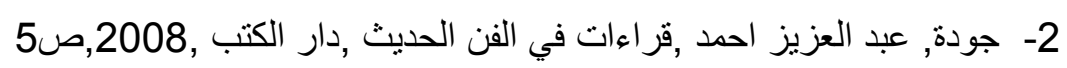

2-jawdat, eabd aleaziz 'ahmad, ,qra'at fi alfan alhadith,dar alkutub,2008,s5

3حسن,محمد أبو الفتوح 2009: الدذهب الاختزالي واثره على التصميم الداخلى والاثاث ,رسالة ماجستير ,كلية فنون

تطبقية جامعة حلو ان ص الفن 85

3-Hasan, Muhammad Abul-Fotouh 2009: almazhab alaikhtizaliy wa haroh ala el tasmem el dahaly wa elatath

4-خليل , نادية محمود : مكملات الملابس فن الاناقه والجمال ، دار الفكر العربي ,ط1, 1999,ص32 4-khulayl, nadiat mahmud : mukamalat almalabis fan alanaqih waljamal , dar alfikr alearabiu ,t1, 1999,s32

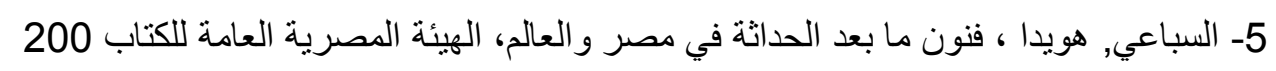

5-alsbaey, huaydaan, fanun ma baed alhadathat fi misr walealim, alhayyat almisriat aleamat lilkitab

5- سميث ,ادور لويس: الددركات الفنية ,ترجمة اشرف عفيفى, الدجلس الاعلى للثقافة القاهرة,1997م ,ص172 6- amith ,adawr luysa: almudrakat alfaniyat ,trajamat 'ashraf eafifaa ,almajlis al'aelaa lilthaqafat alqahirt, $1997 \mathrm{~m}, \mathrm{~s} 172$

6- السيد, هيام العدوى 2011:الأبعاد الفلسفية والتشكيلية لفن المنيمال كمدل لاثراء المشغولة النسجية رسالة دكتوراه

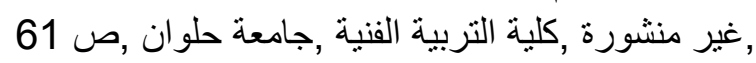
7-alsyd, hiam aleadwaa 2011:al'abead alfalasafiat waltashkiliat lifan almanimal kmdkhl lathra' almashghulat alnasjiat, rsalt dukturah ,ghyr manshurat ,klyt altarbiat alfaniyat ,jameat hulwan ,s 61

7- عبد العظيم ,سحر محمود 2019: فلسفة فن المنيمال كمدخل لتدريس الحلى المعننية لطلاب كلية التربية الفنية رسالة دكتوراه ,قسم الاشغال الفنية ,كلية نربية فنية ,جامعة حلوان

8- eabd aleazim ,shr mahmud 2019: falsifatan fin almunimal kmdkhl litadris alhalaa almaedaniat litulab kuliyat altarbiat alfaniyat, rsalt dukturah ,qsm al'ashghal alfaniyat ,klyat nirbiat faniyat ,jamet hulwan

9- عبد اللطيف ,أحمد محمد عفيفي 2011:جماليات التصميم الداخلي فى الفلسفة المعاصرة ,رسالة دكتوراة,قسم التصميم الداخلى و الاثاث ,كلية الفنون التطبقية ,جامعة حلوان . 9-eabd allatif ,ahamad muhamad eafifi 2011:jamaliat altasmim alddakhilii fa alfalsifat almueasirat, rsalt dikturat,qisim altasmim aldakhla walathath ,klyt alfunun altatbuqiat, jamaeat hulwan .

10- فؤاد ,دنيا امين 2011: تفعيل التصميم الداخلي و انعكاسة على التنمية الانسانية رسالة ماجستير , كلية الفنون التطبقية

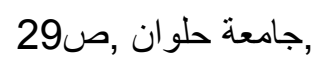

10-uad ,dniya 'amin 2011: tafeil altasmim alddakhilii waineikasat ealaa altanmiat al'iinsaniat ,rsalt majstyr , kuliyat alfunun altatiqiat ,jameat hulwan ,s29

11- مارشال, براند :تعليم ما بعد الداثة ـ الدتخيل و النظرية ,ترجمة: السيد امام ,المشروع القومي للترجمة ,المركز

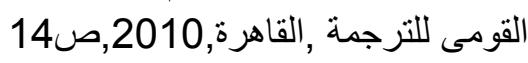

11-marshal, barand :tealim ma baed alhadathat - almutakhiil walnazariat ,trajmata: alsyd 'amam ,alimashrue alqawmii liltarjmat, ,almarkaz alqumaa liltarjimat ,alqahrt,2010,s14 
12- محمد , علا سمير 2006:العمارة الذكية و أثرها على التصميم الداخلى و الخارجي ,رسالة دكتور اه فننون تطبقية ,جامعة

12-muhamad ,ela samir 2006:aleamarat aldhakiyat wa'athariha ealaa altasmim aldakhla walkharijii ,rsalt dukturah ,fnun tatbuqiatan, jamaeat hulwan s 209

13- مختار العطار 2000: افاق الفن التثكيلى على مشارف القرن الحادى والعشرين ,دار الثروق ,الطبعة الاولى,ص

13- mukhtar aletar2000: afaq alfani altashkilaa ealaa masharif alqarn alhadaa waleishrin ,dar alshuruq ,altabeat al'uwlaa ,s 16

-14-Nigel Wheale, The Postmodern Arts: An Introductory Reader, Routledge, London\&NewYork, 1995 ,p6

- 15-Pamela M.Lee, New Game: Postmodernism After Contemporary Art, Theories of Modernism and Postmodernism, the visual Art,V4, Routledge, Taylor \&Francis,2013,p33

16-Christopher Butler, Postmodernism: A Very Short Introduction, Oxford university press, New York , 2002,p25

17-Ingo F. Walther and others, Art of 20thCentury, Part1 , Taschen,2012,p40

18-John Elderfield, Modern Painting and Sculpture, 1880 to the present,The museum of Modern Art, New York, 2004 ,p1 1

19-Jonathan Fineberg, Artsince 1940, strategies of being, second edition ,Laurence King, 2000 ,p50 